\title{
ESTUDIOS
}

\section{Destino Personal y Destino Nacional en el Martín Fierro}

\begin{abstract}
"Pero si tuviéramos que buscar un libro que nos diera la historia argentina, el ambiente argentino, ese libro sería el Martin Fierro". (Jorge Luis Borges, El gaucbo Martín Fierro, Diamante, XV, Londres, 1964, p. 36.)
\end{abstract}

El Martín Fierro no es sólo la obra cumbre de la literatura gauchesca, como dijo Menéndez y Pelayo, sino también, como lo advirtieron Unamuno, Azorín, Lugones y Borges, la máxima contribución que las letras del Nuevo Mundo de habla española dieron a la historia literaria del siglo Xix. Y lo es tanto por el logro con que se ejecuta una voz poética cuanto por la visión que da de una realidad que constituye la circunstancia decisiva del destino de un país en formación y del elemento humano que con ese destino ha de sobrevivir o perecer. De ahí que la obra de José Hernández sea, a la vez que representativa de una singular modalidad literaria, el documento más efectivo que registra la formación de una nacionalidad. Precisamente por este contenido histórico-vital, hoy me propongo ver al Martín Fierro como obra que trasciende el mero canto verbal y se prodiga hacia el centro de una verdad de vida que es, para nosotros los argentinos, un principio de búsqueda individualizante, a la vez que razón de ser de una nación que, paradójicamente, trata de hacerse, de fundarse, en conflicto con una parte fundamental de su pueblo. Por eso, el Martin Fierro expresa cabalmente lo que hemos propuesto para estas reflexiones: un destino personal en pugna con el destino que ha de asumir el país. Y esto de destino personal no lo decimos sólo por lo que se refiere a la persona del gaucho - sean uno o todos los gauchossino en un sentido más lato, que concierne a la autenticidad del destino propio de los argentinos. Evidente contrasentido -insistimos- de un país y unas gentes que quieren determinarse a sí mismos - ser, en una palabra- - con un salto histórico que rechaza su condición más vẹdadera 
y hasta el más elemental principio genético de la evolución. Salto y desvío histórico que no es, claro está, exclusivo de la Argentina, pero que allí se consumó como un hecho radical y total, ya sea por una elección más audaz o más precaria (no lo sé), pero, en todo caso (y ésta no es sólo una tesis de Borges), porque la "historia argentina puede definirse sin equivocación como un querer apartarse de España, comc un voluntario distanciamiento de España" (Discusión, p. 158). Convienє insistir y ahondar en el sentido de ese rumbo como fondo y secuela de un conflicto de culturas que en la cuenca del Plata adquirió conciencia dramática inmediatamente después de la ruptura con la Metrópoli. Resultado, en principio, de una dualidad que constituye la esencia de la gestación de Nuestra América, pero que en las pampas rioplatenses se definió en la ejecutoria de un bacer aniquilando, o, por lo menos, anulando. Hacer que, en esta dialéctica, equivale a destino nacional, y aniquilar o anular, que determina el destino individual.

Es obvio que la Argentina fue el primer país hispanoamericano que quiso hacer tabla rasa de su pasado, precisamente porque no tenía tal pasado como dinámica de futuras realizaciones, sino los signos que demoraban su constitución como organismo que aspiraba a una función de actualidad. Ser contemporáneo de lo más avanzado de la civilización moderna era un desiderátum que exigía una suerte de muerte civil en masa. $\mathrm{E}$ implicaba una toma de posición sin contemplaciones melancólicas del espacio y del tiempo y sin gestos humanitarios para el hombre que detentaba esa especie de edén sin usufructos. Digamos que las huestes del progresismo moderno entraron en las bucólicas pampas para imponer (ésa es la palabra) un nuevo régimen, que suponía una alteración total de las relaciones del hombre con su mundo. Especie de monismo tecnocrático que suplantó violentamente la dualidad tradicional en que moraban los dominios de España. Está claro que cuando Menéndez y Pelayo, Azorín, Unamuno, etc. elogian y reclaman al Martin Fierro como parte y continuidad de lo hispánico, lo que se postula es un rechazo de esa invasión de la Europa moderna.

La historia es bien sabida.

En general, toda Iberoamérica nace bajo el signo de una dualidad irreconciliable: señores y vasallos, explotadores y explotados, ricos y pobres, ilustrados e ignorantes, extranjeros y nativos, desde la llegada de los conquistadores. La situación se continúa en la época de las luchas por la independencia y no se subsana con la organización nacional: unitarios y federales, conservadores y liberales, dictaduras e intentos de democracia republicana, ciudad y campaña, civilización y barbarie, etc., etc. En las regiones donde los imperios prehispánicos no habían logrado 
un desarrollo más o menos orgánico, la necesidad de remediar esos males fue más urgente, y también, por lo mismo, fue muy obvia la falacia de la velocidad. La Argentina es el caso, por demás evidente, de los efectos de la urgencia civilizadora, y también, según Martín Fierro (o José Hernández), no ya de la falacia, sino de los estragos de la misma. Hasta cierto punto, la Argentina podría ser considerada como el país modelo en el desarrollo cultural, político, social y económico de Iberoamérica, pero a condición de que ese carácter modélico no se vea como una serie de características coincidentes con el resto de la América Hispánica. Porque la Argentina surgió con la total convicción de una ruptura no sólo con España como entidad política, sino con todos los módulos básicos de la cultura hispánica. Modelo de rebelión y aspiración a una independencia que debía negar, como principio de vida y acción transformadora, a sus hermanas repúblicas en liberación. Digámoslo sin ambages y sin mengua para nadie, la Argentina nació y creció de espaldas a España y a Hispanoamérica. Las declaraciones de los hijos de Mayo son tantas, en este sentido, que huelgan las citas. Lo que importa aquí es destacar ese rumbo tomado por los gobernantes argentinos, porque él es el que determina la suerte del elemento más hispánico que quedaba como rezago que había que eliminar de la pampa: el gaucho y sus signos vitales: su visión del mundo, su actitud humana, el sentido de su participación en la nueva nación, que se levanta para llenar el vacío espacio del desierto con las ventajas del progreso. $\mathrm{Y}$ ese progreso fue, primero, el acumulativo, liberal e ilustrado del siglo Xvir, y luego, el más selectivo y hasta discriminatorio, por especializado, del siglo Xix. El gaucho fue el principal elemento en juego en este proceso transformador. Por ser el más ligado (si no el único) al status que sé deseaba destruir y reemplazar, fue quien sufrió el mayor deterioro, hasta sucumbir en su condición de tal, por muerte física (en la frontera o no) o por violenta imposición de cambio. El Martín Fierro de Hernández y el Facundo de Sarmiento captan y exponen, con la convicción y el dramatismo de la hora que se vivía, el conflicto existencial de la Argentina: dos actitudes y dos partidos a seguir, el europeo y el americano, como lo ha señalado el francés Guizot. Para unos, los seguidores de la cultura europea moderna, era cuestión de civilización o barbarie, como enfatiza, sin perspectiva histórica, $y$, por tanto, hoy sin la validez de entonces, el libro de Sarmiento. Para los partidarios de una democracia cultural aplicada a una racional educación del pueblo, era simplemente una cuestión de dos políticas (título de un admonitor estudio de Hernández), políticas que enraizaban en los rumbos que el país iba a tomar en materia de economía: agricultura, ganadería, incipiente industrialización, función suministradora de una pro- 
ducción agropecuaria para potencias mundiales que necesitaban la materia prima. No mucha elección por cierto, porque nuestros progenitores de la Patria Grande (que dijo Lugones) fueron tan condicionados como condicionantes. Lo primero estaba dado por la naturaleza y sus productos, y lo segundo, por la aceptación de valores que venían prestigiados de hecho, desde arriba, según modelos ya altamente elaborados y sin demora para la adquisición y el usufructo. El experimento de Rivadavia, primera visión de despotismo ilustrado para una nación todavía nonata, es un caso único de apremio transformador, y las recomendaciones de Echeverría y sus compañeros de la proscripción suelen tener visos de angustia y desesperación frente a la parálisis de la dictadura rosista. Frente al Matadero el Dogma socialista; frente a la pulpería la escuela, que debía empezar por educar al soberano. Gobernar era poblar, y poblar significaba hacer de la pampa de gauchos e indios un paraíso terrenal. Sembrar la tierra era lo mismo que sembrar el espíritu. Agricultura y cultivo de las almas y las mentes fueron sinónimo en la acción. Y aquí otra vez la oposición de criterios: la convicción criolla y la cosmopolita. Hernández parecía estar convencido de que las tareas pastoriles producían hombres valientes y generosos, y que la agricultura o la industria los hacía apocados y avaros. Individuo frente a persona, que es como decir: autenticidad frente a lo falsificado. En 1874, Hernández, en carta a los editores de la $8^{\mathrm{a}}$ edición de Martín Fierra, todavía insiste en su empeño por salvar el babitat del gaucho y su respetabilidad. Dice:

En nuestra época un país cuya riqueza tenga por base la ganadería, como la provincia de Buenos Aires y las demás del litoral argentino $y$ oriental, puede no obstante ser $\tan$ respetable y $\tan$ civilizado como el que es rico por la agricultura, o el que lo es por la perfección de sus fábricas. . La ganadería puede constituir la principal y más abundante fuente de riqueza de una nación, y esa sociedad, sin embargo, puede hallarse dotada de instituciones libres como las más adelantadas del mundo... y puede poseer Universidades, colegios, un periodismo abundante e ilustrado, una legislación propia, círculos literarios y científicos.

Hernández parece estar describiendo aquí la Argentina forjada por Mitre y Sarmiento, y muestra, sin duda, sus convicciones de La vuelta de Martín Fierro, o sea, al gaucho convertido en paisano que se allega a una estancia para ver si lo dejan trabajar. Pero la denuncia queda formulada como protesta por la pérdida de lo que los sociólogos llaman una clase-ein-si, transferida a una clase-paratotro (o para nadie), sin haber podido llegar 
a ser una close-para-si. Y aquí entra a jugar el punto de vista en que nos coloquemos para interpretar la disyuntiva del destino propio de los argentinos. ¿La clase culta, la que hizo de la Argentina un país con progreso, riqueza de materia prima y cultura digna de la Europa moderna, debía seguir los patterns de una vida pastoril e inadecuada al tiempo en que se vivia? ¿O esa misma clase tuvo razón en hacer lo que hizo: doblegar el destino personal del gaucho en favor de un destino nacional argentino? Las dos respuestas se hallan en la "Ida" y la "Vuelta" del Martín Fierro. Hernández, que era un hombre culto y de la ciudad, más que el gaucho en sí, lo que quería era retener parte de sus virtudes nativas -y no más-, como condición del hombre de esas tierras, según el telurismo romántico y por oposición a las alienaciones del positivismo, siempre avaro para el ser humano, y excesivamente generoso para la voracidad de todos los industrialismos. $\mathrm{Y}$ aquí nos parece oportuno recordar que el Martin Fierro fue el primer reclamo de justicia social en Argentina, y también el mayor fracaso de ese reclamo. Lo que más le apenaba a Hernández era el despojo que se hacía al nativo en nombre del progreso y de la civilización. No es necesario insistir en esta acción oficial, que marca uno de los períodos más injustos y vergonzosos de la historia argentina. Pero sí conviene destacar la actitud de Hernández como una resistencia esencial al avance del positivismo. En este sentido Hernández fue un romántico, acaso el más idealista y lírico de nuestros románticos, por su fe en la inmanencia de los derechos del individuo $y$ en la natural adaptación a sus condiciones de existencia.

El positivismo significó la entrada de la planificación en la vida del individuo en sociedad, on otros términos, la aplicación de ciertos métodos de coerción y enajenación que actuaron sobre la libertad y la conciencia personales como un fatalismo irremediable. Ante tales atropellos, se ha sostenido que el Martín Fierno es el poema de la dignidad del hombre; en todo caso lo sería de la dignificación del gaucho, tarea que empieza con la exaltación de sus cualidades desde la independencia $y$, en especial, con el nuevo modo de valorar la condición humana que encararon los románticos.

Entre las muchas interpretaciones que podemos dar al romanticismo hay una que me parece fundamental: la da un poeta $y$ notable pensador norteameticano: T. E. Hulme. Dice así (doy mi traducción): "He aquí la raíz de todo romanticismo: el hombre, el individuo, es una infinita reserva de posibilidades; y si podemos reordenar la sociedad mediante la destrucción de todo orden opresivo, entonces esas posibilidades tendrán la oportunidad de realizarse, y así lograremos el progreso". ${ }^{1}$

1 Speculations (London, n/d, p. 116). 
A partir de ese principio de posibilidad, que está en la base del hacer conociendo y del conocer haciendo de pensadotes como Herder y Vico, Echevertía formuló un programa ecléctico y sensato como plataforma para nuestra organización, con un sentido nacional y americano, a la vez que cosmopolita y universal, pero sin genocidios ni enajenaciones subordinantes. A partir de 1837, y acaso por la urgencia de liquidar la dictadura de Rosas, la visión de Echeverría fue llevada y traída según las necesidades y conveniencias de los intereses en pugna. Entrar en los detalles del proceso de esta edad conflictiva de la Argentina no es posible ahora. Hay, por lo demás, una abundante bibliografía para una clara y documentada presentación de las luchas sociales, económicas y políticas de la época que venimos tratando. ${ }^{2}$ Lo que me importa consignar ahora es que en la formación del destino nacional argentino, determinante del destino personal del gaucho, intervinieron tres grupos sociales, políticos y económicos bien diferenciados: 1) la burguesía productiva del interior sostenida por el caudillismo de las provincias de más conservadorismo hispánico; 2) su antítesis: la burguesía exportadora de Buenos Aires, sostenida por las grandes potencias imperialistas, especialmente Inglaterra, y 3) una especie de síntesis: la burguesía ganadera del litoral, que buscaba una solución más modesta y lenta, pero más propia, al problema del establecimiento de una nueva nación con gatantía y sello propios. En este tercer grupo debemos colocar la línea Echevertía-Hernández, por lo que Echeverría tiene de adaptación, aceptación y rechazo de la cultura europea, y por lo que Hernández representa como equilibrio entre el hombre y su mundo. La filosofía de ambos nos enseña que no hay que violentar a la naturaleza ni al hombre con pretendida fórmula de superación cultural, porque entonces no tendremos ni naturaleza, ni hombre, ni cultura. Ambos fueron cautelosos en lo que respecta a la adaptación de sistemas de vida y culturas más prestigiosos, porque pensaban que lo de arriba somete y sustituye a lo de abajo y que era preferible elevar antes que someter o reemplazar. Creían en la evolución y el progreso, pero como un proceso lento y natural y no con esa celeridad propia de las imposiciones científicas. La obra de Hernández, como la de Echeverría, quiso ser la comprensión del hombre en su medio, y para ello estos dos pensadores-poetas no tuvieron más misión que exponer al país tal como exa: al medio, la pampa, con sus facturas geo-topográficas; al hombre, el gaucho ( $y$ accidentalmente el indio), con una presentación verídica, con sus modos de vida, sus psicologías, escenario habitual, producciones,

2 Estudios de José Luis Romero, Samuel Schneider, Horacio Giberti, Aldo Ferrer, Aníbal S. Vázquez, N. Galasso, Enrique Rivera, B. Rabinovich, Néstor Eduardo García, etc. 
y su propio lenguaje. Hernández, sobre todo, creía en una ley natural, orgánica, con un sentido que no difiere mucho del evolucionismo de Darwin, tan efectivo en la tarea de contener la desenfrenada instintividad romántica. Hacia 1850 se hizo lugar común en toda Europa la proposición darwiniana de que la naturaleza no progresa a saltos, sino que las especies entran en la existencia mediante el efecto acumulativo de pequeñas varia. ciones. Una hipótesis contraria fue propuesta por el botánico holandés Hugo De Vries (1848-1935), quien sostuvo que cada especie viene al mundo y entra en su estado de existencia definitiva, no por pasos de evolución gradual, sino de un solo salto, por el cual queda definitiva y absolutamente fijada. Esta doctrina fue la aplicada por los ilustrados del partido europeo: Mitre, Sarmiento, etc., y ya como sistema político de acción ejecutiva, por el Partido Unitario, instrumento de penetración extranjera y de extirpación nativa, bajo la consigna de lo que para la época de Rosas parecía inobjetable: la civilización, la cultura; el orden, la paz, la seguridad social, el prestigio moral y espiritual, el régimen legal de las instituciones que garantizan la libertad individual y los medios de convivencia. El positivismo spenceriano y la sociología de Comte dieron las pautas en la realización de este nuevo destino de la nación argentina. $Y$, como dijo Rafael Obligado en su poema Santos Vega, eso fue para el gaucho, ya convertido en payador simbólico de una pampa hecha granero y mercado de carnes, el mismo diablo en persona; la ciencia del positivismo aseguró el destino nacional argentino, con la muerte de lo que quedaba de su pasado hispánico: el alma romántica del gaucho, presencia de una ausencia que es elegía de un ser perdido \& canto irrecuperable de amor a un ideal no logrado. Mitre, Sarmiento, Avellaneda, Roca, forjadores del destino de inuestra patria, dieron su lección de modernidad con denuedo civil y arrojo de poseídos. Hernández dio su lección de humanidad y su Martin Fierro también. En aquéllos, acción y nación son funciones consecuentes. En Hernández, autor y personaje, son designios concurrentes: arte y vida en una visión encarnada del mundo y en una realidad poética. En ambos, funciones y designios, vemos el testimonio de una verdad histórica, o sea, temporal, relativa, a la vez que una verdad más trascendente: la que es eterna porque es el establecimiento de nuestro ser en el mundo, tanto el de la historia como el del arte. Existimos gracias a Sarmiento y a Hernández, y somos porque nacimos y vivimos con el Facundo y el Martín Fierro, destino nacional y personal, origen y voz de nuestra verdad histórica. Pero una voz, como vimos, que ha debido sacrificar su destino individual en pro del destino nacional. $O$, por lo menos, como Hernández la propone en su poema, una voz que se aprieta en huidas y desplazamientos, que no son búsquedas 
de "sonidos" ni hallazgos de tealizaciones plenas, sino acumulaciones de silencios, a pesar de que el gaucho dice que canta con toda la voz que tiene. El Martin Fierro es la epopeya hispanoamericana del silencio y del desamparo. David Lagmanovich hace interesantes observaciones sobre el valor de la palabra y la función del silencio en esta obra de protestas y denuncias a voz en cuello de cabo a rabo (véase pp. 279-286 de este número). Pero silencio y desamparo no implican renunciamientos. El protagonista que narra sus propias desventuras no se amilana y trata una y cien veces de romper los muros que estrujan su destino. Martín Fierro tiene una voluntad y hasta un optimismo dignos de mejor causa. Pero todo es en vano: la ley es la del embudo y la justicia no llega a las puertas del gauchaje. El destino de una nación (su ex-patria de tiempos dichosos) se ha cumplido, pero para el gaucho es un cumplimiento al revés. La voluntad del gobierno es atroz; las levas son su baldón y escarnio; el fortín, una iniquidad y el más humillante oprobio. El gaucho ya no puede dar nada de lo mejor que él puede of recer y que ya había dado a la Patria: su valor, su lealtad, su honradez, su amor a la libertad y su incomparable don de confraternidad humana: ese espectáculo de amistad y de bonanza que tanto exalta Borges como mérito de algunos poemas gauchescos. Martínez Estrada ha podido hallar en el Martin Fierro una concepción kafkiana de la existencia: la del encierro y postergación sin espetanzas. Martín Fierto es un desalojado, un marginado político-social, un enajenado de su babitat; los otros le han violado su ser como a una criatura impotente o un simple objeto innecesario e indeseable. Ha sido privado de los dos dones que, según Martín Fierro, definen la condición humana: la palabra y la amistad. Se hace matrero, busca, "infierno por infierno", el que está más allá de las fronteras, a donde no llega la autoridad de los que gobiernan. Martín Fierro es un desterrado que ahora ha de comenzar a crearse en sí mismo, en la extraña lejanía de un mundo de barbarie. Rehacer su destino como una continuidad de la ausencia, un ser del desamparo, una intencionalidad del silencio, $o$, si se quiere, la misma voz del desierto. Porque todo él está desierto, es el desierto y habla para el desierto, a pesar de que canta males que padecen todos, a pesar de que su canto

no es para mal de ninguno sino para bien de todos.

A esta altura de mi exposición debo reconocer, con Antonio Pagés Larraya, la dificultad extrema que ofrece el Martín Fierro "para situarlo dentro del marco conceptual y de la Zeitgeist de su época". Ante todo, "se 
lo percibe como una obra que está fuera de la modernidad," admitimos con el crítico. Al mundo urbanizado y burgués, al progresismo ilustrado y las transformaciones iluministas o de la tecnocracia industrial, es obvio que opone "la básica inalterabilidad de las nociones esenciales". A la crisis de la concepción religiosa de la existencia le enfrenta una vida cargada de religiosidad y superstición; a los hallazgos del saber científico le opone un conocer por la experiencia y la memoria ("porque eso tiene otra llave/ y el gaucho tiene su cencia"); al intelectual, al literato y hombre cultivado lo confronta con el hombre tal como es in naturam; al cosmopolitismo, mundanidad y brillo del 80 , contesta con una opacidad huraña, y al optimismo decimónico prefiere una marcada angustia existencial. (Véase pp. 231-243 de este número).

Borges asegura que "...si tuviéramos que buscar un libro que nos diera la historia argentina, el ambiente argentino, ese libro sería el Martin Fierro (El gaucho Martin Fierro, Diamante, XV, Londres, 1964, p. 36.). Pero esto apenas si toca el lado histórico-local del poema, punto de controversias de estériles nacionalismos (Borges escribe hacia los 30, años de cerrazón nacionalista bajo la dictadura de Uriburu). Calixto Oyuela fija, con otra intención, los alcances de ese contenido del libro:

El asunto del Martin Fierro no es propiamente nacional, ni menos de raza, ni se relaciona en modo alguno con nuestros arigenes como pueblo, ni como nación políticamente constituida. Trátase en él de las dolorosas vicisitudes de la vida de un gaucho en el último tercio del siglo anterior, en la época de la decadencia y próxima desaparición de ese tipo local y transitorio nuestro ante una organización social que lo aniquila. (Antología poética hispanoamericana)

Borges y Oyuela tienen razón, si admitimos que esa razón se sitúa en lo más relativo de la verdad que apuntan. Porque en este insólito librito, que como alegato político, en su voluntad implacable de denuncia, "debía ofrecer la imagen cruda de un deplorable momento histórico argentino, lo cual significaba componer un friso donde alcanzara relieve la pulpería, el fortín, la cárcel, el pajonal, los aduares; perfil de jueces, alcaldes, comandantes, soldados, gringos y pulperos", ${ }^{3}$ como poema (o sea como transferencia de esa realidad hecha por un creador) llega a ser en manos de Hernández un atormentado despliegue en el cual esas imágenes de la historia más cierta actúan explosivamente desde dentro del acto

3 Ara, La poesia gaucbesca, p. 51. 
arbitratio del atropello, la persecución, el despojo, la pelea, la tortura, el malón o los estragos de la peste. $\mathrm{Y}$ de lo circunstancial y circunscripto se eleva a una red de formulaciones que penetran desde las raíces del hombre y se instalan en su ser y su conducta como propiedades especificas de la condición humana: la libertad, la conciencia de actuar (en un orden más natural que legal), su noción de igualdad, justicia, honestidad, prudencia; de relaciones de las causas y los fines, de las necesidades y obligaciones, del poder y la obediencia; todo juega su papel dentro de una concepción del universo y de la vida que sorprende por la coherencia de su estructura, como surgida de leyes eternas de la naturaleza o de Dios. Se explica, por tanto, que el poema entero redunde en planteos sobre el origen y destino del hombre, sobre la libertad y el determinismo en un mundo en donde lo transitorio y la permanencia son decisivos para la existencia humana. Es indudable que el hombre y sus atributos diferenciales son el objetivo fundamental de Hernández, y que la situación real que lo determina en un contexto preciso de tiempo, espacio y circunstancia histórica es un pretexto que da vigencia a necesidades de un hombre de partido. O sea que, más allá de esa función necesaria que el ciudadano - el legislador Hernández debe cumplir como adversario de Mitre, Sarmiento, etc., está la fundamentación ontológica ( $\mathrm{y}$, sobre todo, ética) del hombre argentino, como hombre en sí, realizado en su condición y virtudes más genuinas. Pero Hernández no parece separar ese destino último de su personaje, propuesto como categoría modélica, del protagonista (o agonista irreversible) de un problema surgido de la experiencia y esgrimido como condena de un sistema, al fin y al cabo, de educación común, como lo veía Sarmiento. Hernández quiere ser concreto, verídico, lo más realista posible. Pero un fondo de tradición cristiana e hispánica lo empujan hacia un pensar trascendente en el que la Providencia juega su carta mayor. A poco de entrar en la lectura del poema, nos enteramos de que "en el Martin Fierro mundo y hombre son creaciones de Dios; que el universo moral y el universo físico responden a leyes igualmente dadas por el Ser primero; que Dios, el cielo, el infierno, santos y ángeles, personas divinas y humanas, integran un todo regido por principios de armonía y de equilibrio" (Ara), que no es dado a los mortales alterar. De lo que puede inferirse que lo que éstos hacen, para bien o para mal, ha de servir menos para el designio humano que lo que ya está decretado por el Creador. Y no me refiero sólo a la famosa payada con el negro. Al principio del Canto XIII, las desventuras de Fierro y Cruz quedan sentadas en generalizaciones de la condición humana, incluidas con el obvio desea de potenciarlas en las infalibles leyes del Divino Hacedor: 
Dios formó lindas las flores, delicadas como son:

les dio toda perfección

y cuanto él era capaz;

pero al hombre le dio más

cuando le dio el corazón.

Le dio claridá a la luz, juerza en su carrera al viento, le dio vida y movimiento dende l'águila al gusano, pero más le dio al cristiano, al darle el entendimiento.

Este dón de ascendencia aristotélico-tomista es lo que ha de resolver el destino personal en el plano de la conducta, plano del hacer como decisión y tiesgo, como naufragio o salvación, según el uso adecuado que el hombre haga de esa "prudencia que Dios le dio". Fierro se lo dice al hermano del negro que mató en una pelea y en un trance de suprema definición para su vida:

Saber el hombre guardarse

es la gran sabiduría.

Compárese este juicioso repliegue con las bravatas y autosuficiencias de la primera parte y se verá que el destino personal de Martín Fierro, gaucho real y personaje de otro destino que lo incluye, se cumple como un lento aprendizaje de anulaciones $y$ por un proceso, por tanto, de desencuentros y desintegraciones del ser, que debe reajustarse en la ley divina y humana de la obediencia. Y bien que Martín Fierro sabe el precio que debe pagar y lo que ha de redundar en beneficio de uno y de todos:

El que obedeciendo vive

nunca tiene suerte blanda;

mas con su soberbia agranda

el rigor en que padece;

obedezca el que obedece

y será bueno el que manda.

El destino personal se cumple en el Martín Fierro por un proceso de eliminaciones que van desde la pérdida de su libertad, su casa, hacienda, mujer e hijos, su tierra, su posible nuevo empezar en la barbarie india 
y hasta la propia conciencia de su valer, superforjada fuera y al margen de las normas que rigen la vida civilizada. El plan del destino nacional ejecutado desde la "autoridá" del gobierno se ha cumplido, pero nos deja una duda acerca de su validez en cuanto a la ambigüedad de si Fierro es simbólicamente un cadáver de ese destino nacional o, lo que es peor, el remanente de una ausencia, presencia de una inexistencia que apunta su dedo acusador hacia la inautenticidad, el desarraigo, la falta de una verdadera tealidad del hombre argentino. Es decir, su condición de "ser destinado", de no haber tenido nunca poder de decisión sobre su propio destino. Dualidad, otra vez, cuyos resultados fatales se vienen ahondando día tras día. Destino nacional que se quiere forjar sobre la muerte del destino personal es, por lo que hemos visto, la creación de un anti-destino que sólo puede dejar a un país, una nación y a su pueblo fuera del recinto protector de la historia. Esta, claro está, es más bien una preguntá, pero se cierne sobre la verdad del caso argentino como una sombra, que es más una duda que una respuesta. Si lo comparamos con un caso similar, el norteamericano, ¿quién no podrá comprobar que en la Argentina no se logró ese milagro de integración masiva de individuo y mundo, sociedad, ley y sistema que dio la grandeza y el poder que hoy gozan los norteamericanos. País aluvional, el destino nacional argentino se fundó en el desarraigo - una manera de ser-, y puede decirse que todavía mora en la esperanza de nuestra fe mítica. La inmadurez política, social, económica de la Argentina de hoy, como nación, es proporcionalmente opuesta a la de sus creaciones culturales, como las literarias de Hernández, Sarmiento, Borges, Cortázar, las artísticas de un Victorica, Spilinbergo, Le Parc o Ginastera, y las científicas de Housay o Leloir, nombres que suenan con sonidos más propios en Europa que en Indoamérica. Esto plantea, desde luego, problemas mucho más vastos $\mathrm{y}$ hondos, que no me atrevo a afrontar, pero que pongo a disposición de los interesados para una discusión que pueda abrirnos un camino o darnos alguna luz, a nosotros, los tan engreídos y deslumbrados argentinos.

AlFredo Roggiano

University of Pittsburgh. 